Sharif University of Technology
Scientia Iranica
SCIENTIA
IRAN ICAA

\title{
The objective design of triangular bucket for dam's spillway using Non-dominated Sorting Genetic Algorithm II: NSGA-II
}

\author{
S.H. Hojjati ${ }^{a}, 1$, S.H. Hojjati ${ }^{\mathrm{b}}$ and S.A.A. Salehi Neyshabouri ${ }^{\mathrm{c}, *}$ \\ a. Faculty of Civil and Environmental Engineering, Tarbiat Modares University, Tehran, Iran. \\ b. Faculty of Electrical and Computer Engineering, Babol University of Technology, Babol, Iran. \\ c. Water Engineering Research Institute, Faculty of Civil and Environmental Engineering, Tarbiat Modares University, Tehran, \\ Iran.
}

Received 10 August 2014; received in revised form 23 September 2015; accepted 24 November 2015

\section{KEYWORDS}

Triangular flip bucket; Chute spillway width; Ski jump; NSGA-II algorithm; Karoon III dam.

\begin{abstract}
Ski jump is one of the most effective structures in energy dissipation over spillways. Spillways have long been of practical importance to safety of dams. The major criteria in hydraulic design are based on the analytical and empirical methods. In the current study, in order to increase chute spillway efficiency, a multi-objective evolutionary algorithm known as the Non-dominated Sorting Genetic Algorithm II (NSGA-II) has been utilized to design the optimal triangular bucket angle and chute width. In design method, two separate objective functions have been used. In the first objective function, equations of dynamic pressure of the bucket, the jet length after bucket, and the scour depth have been used. The second objective function is related to construction volume of chute spillway. For calibrating the first objective function, characteristics of Karoon III dam have been used as a case study. The difference between design parameters of Karoon III spillway and those from NSGA-II algorithm method is less than 12 percent. According to the results, if the jet length is considered as the most impressive parameter in the first objective function, design of the spillway becomes frugal.

(C) 2017 Sharif University of Technology. All rights reserved.
\end{abstract}

\section{Introduction}

In hydraulic engineering, structures like stilling basins, baffled aprons, and vortex shafts are used as energy dissipaters [1]. The main role of these structures is to transform or dissipate excessive energy of fluid flow. Ski-jump dissipaters are utilized in situations where the kinetic energy of flow is high and can cause

1. Present address: Faculty of Civil and Environmental Engineering, Amirkabir University, Tehran, Iran.

*. Corresponding author. Tel.: +982182883316; Fax: +982182884914

E-mail addresses: hamihojjati@yahoo.com (S.H. Hojjati); hani.hojjati@yahoo.com (S.H. Hojjati); salehi@modares.ac.ir (S.A.A. Salehi Neyshabouri) damages like erosion in the tail water channel, abrasion of hydraulic structures, and production of destructive waves downstream.

Most researches on this field have been done on circular buckets. Juan and Hager [2] experimentally investigated the effect of Froude number and bucket geometry on dynamic pressure distribution for circular flip buckets and compared the results with theoretical equations. Heller et al. [3] extended Juan and Hager's [2] circular flip buckets experiments in order to study pressure distribution at the bottom of bucket, flow characteristics for different geometries, and Froude numbers. Their attempts resulted in providing equations for calculation of value and location of maximum pressure. Moreover, they computed jet 
profile downstream of flip bucket and investigated the effect of the both inlet Froude number and bucket radius on jet trajectory. Steiner et al. [4] conducted similar experiment to that of Heller et al. on triangular flip bucket. They compared parameters like the dynamic pressure on bucket and dissipation of energy between the triangular and circular buckets. In another research, Pfister [5] considered different slopes of upstream and downstream channels in his experiments and proposed an equation for length of ski-jump. Pfister [6] assessed the jet takeoff angle and developed an equation by considering the effect of chute spillway slope. Hojjati [7] validated a numerical model (triangular bucket) with Steiner et al. [4] data. Then, he studied dynamic pressure on the bucket, length of jet after the bucket, the energy dissipation, and scour depth.

As one of the valuable researches using genetic theory for flip buckets, it can be referred to studies of Azamthulla et al. [8] who could successfully employ Genetic Programming (GP) in estimation of downstream scour depth. A general multi-objective optimization problem includes a series of objectives and it is related to a number of inequality and equality constraints. Non-dominated Sorting Genetic Algorithm (NSGA) which was suggested by Srinivas and Deb [9] was one of the first evolutionary algorithms. Deb et al. [10] proposed a far more improved version of NSGA called NSGA-II. They said that "because of NSGA-II's low computational requirements, elitist approach, and parameter-less sharing approach, NSGAII should find increasing applications in the years to come". In this paper, NSGA-II method is utilized for optimization of multi-objective function. This method has been implemented for some successful studies: Reddy and Kumar [11] used Multi-Objective Differential Evolution (MODE) method for optimization of reservoir and compared it to NSGA-II. Considering the effect of resource leveling and allocation of strategies on total time and costs of projects, Zahraei and Tavakolan [12] applied two concepts of time-cost trade-off and resource leveling and allocation in a stochastic multi-objective optimization model minimizing the total project time, cost, and resource moments. NSGA-II algorithm has been used to solve the optimization problem. Malekmohammadi et al. [13] optimized series reservoir with short-term objective of flood control and long-term objective of supplying series of river-reservoir by NSGA-II algorithm. For ranking the model results, ELECTRETRI is used. According to the results, ELECTRETRI is capable of ranking the results of multi-objective optimization model. Behzadian et al. [14] presented a new method for water quality management in water distribution systems by applying NSGA-II algorithm for multi-objective booster chlorination.

Regarding ski-jump spillways, it can be concluded that, so far, most researches have been carried out experimentally; they were related to circular buckets. These buckets are usually designed based on empirical equations and with the help of a costly-scaled model. The triangular bucket was first introduced by Steiner et al. [4]. Due to its simple construction, it can be a proper substitute for circular shaped buckets. The angle of deflection is one of the main parameters in bucket design due to the fact that it affects some other important variables, like dynamic pressure distribution on a bucket, jet length, energy dissipation, and scour depth. In this article, a novel approach is provided for designing a flip-bucket. In this method, bucket angle and width of chute spillway are obtained by NSGA-II multi-objective optimization algorithm. In NSGA-II algorithm, it has been attempted to decrease dynamic pressure, scour depth, volume of material which are used in spillway construction and increase jet length in an optimal way. In order to design based on the suggested method, some inputs including design discharge of the spillway and downstream depth for calibrating the equation are needed. This method is completely general and applicable to all triangular bucket spillways. Also, if dynamic pressure, scour depth, and jet length equation of circular flip-bucket are used in the first objective function, this method can be used for this kind of flip-bucket as well.

\section{Tools and methods}

The underlying aim of all optimization problems is to decrease the cost and increase the benefit. This cost and benefit analysis can be defined as a function of decision variables.

Among all optimization methods inspired from nature, the Genetic Algorithm is one of the most fully-fledged approaches. In this algorithm, the process starts by generation of an initial population using random initial search points [15].

Non-dominated Sorting Genetic Algorithm NSGA-II is a kind of multi-objective genetic algorithm that was introduced by Deb et al. [10]. In NSGA-II algorithm, multi-objective evolutionally classic algorithm's mistakes were corrected by non-dominated sorting and sharing parameters. Their mistakes are as follows: 1) computational complexity $\left(m N^{3}\right)$ in which $m$ is number of objectives and $N$ is population size. In other words, by increasing population and sorting each generation, computational cost of evolutionary classic algorithms will severely be increased. NSGA-II method uses non-dominated sorting with computational complexity $m N^{2}$. 2) To reach optimal results, elitism method is not used. In this method, for creation of a new generation, good population of the previous generation was used. This approach has a better performance and converges faster to optimal result. 3) The need for specifying a sharing parameter. 
Since NSGA-II algorithm has been explained elsewhere, the details are not discussed in this paper.

In this research, in order to obtain an optimum angel of bucket and chute spillway width, a Nondominated Sorting Genetic Algorithm II (NSGA-II) has been used. The multi-objective algorithm NSGA-II code is written in Matlab programming language. By getting inputs including design discharge of spillway, Froude number in chute spillway, upstream and downstream depth, this algorithm obtains the optimal value of input depth $\left(h_{0}\right)$, input velocity $\left(V_{0}\right)$, and bucket angle $(\gamma)$. Finally, chute spillway width is calculated by $\left(B=\frac{Q}{h_{0} V_{0}}\right)$.

\section{Case study}

In this paper, to form the objective function, Hojjati's [7] equations are used. As characteristics of his numerical model were in accordance with geometrical and hydraulic properties of the largest spillway of Karoon III, the results have been compared to features of this dam. Karoon III dam (Figure 1) has been built on Karoon River in south of Iran. The dam is a concrete arch structure with height and storage capacity of $205 \mathrm{~m}$ and 2750 million cubic meters, respectively [16]. It consists of 3 spillways: 1) gated chute spillway as the main spillway located on the righthand side; 2) orifice spillway provided as maintenance spillway which is located on the dam body; 3) crest spillway without an embedded gate for emergency conditions [16].

The initial design values for the largest chute spillway discharge rate and Froude number, respectively, are $4917 \mathrm{~m}^{3} / \mathrm{sec}$ and 2.2 . The chute spillway length and width are 117 and 15 meters, respectively.

As the bucket of this dam is circular, the parameters have to be modified for triangular buckets according to the following steps:

1. For transforming $R$ and $\beta$ (radius and angle of the circular bucket) to $w$ and $\gamma$ (height and angel of bucket), Eq. (1), which is obtained through geometrical relation, is used (as shown in Figure 2).

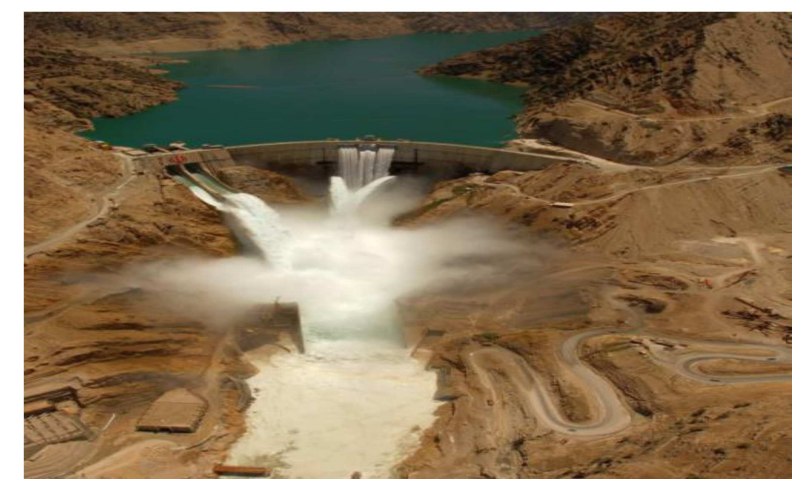

Figure 1. Karoon III dam.

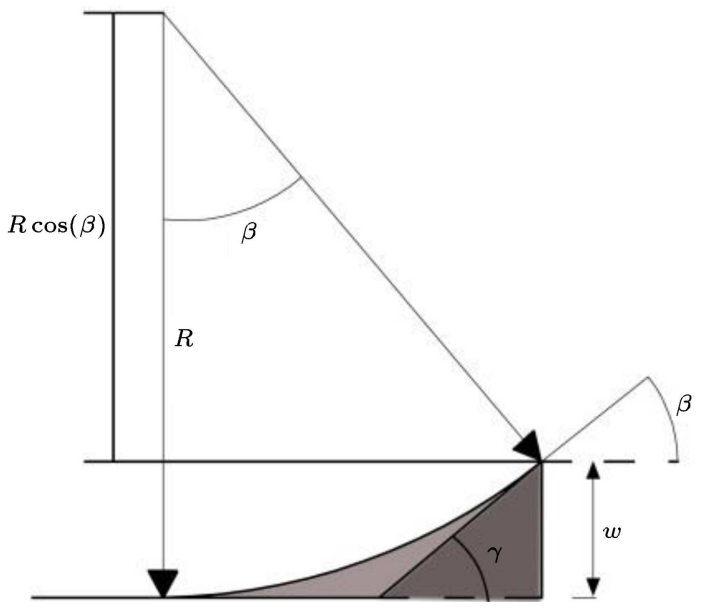

Figure 2. Conversion of triangular flip bucket to circular flip bucket with identical deflector.

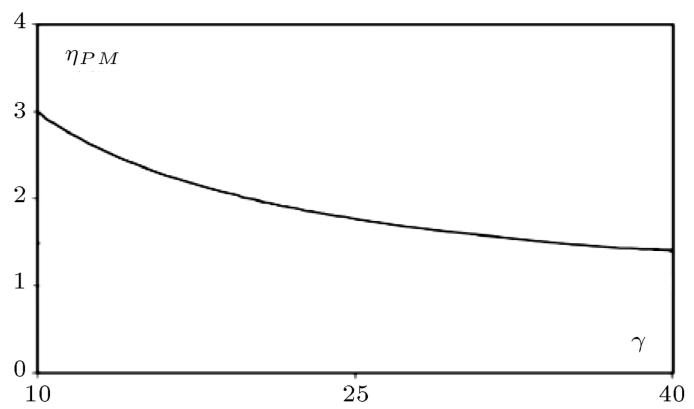

Figure 3. Comparison of dynamic pressure on triangular and circular buckets [4].

Note that all the angles in this article are in degrees:

$$
w=R(1-\cos \beta) \quad \text { and } \quad \gamma=\beta .
$$

Putting Karoon III spillway dimensions in Eq. (1) ( $R=30 \mathrm{~m}, \beta=30$ ), the triangular bucket height and angle would become $4 \mathrm{~m}$ and 30 degrees, respectively.

2. To find equivalent dynamic pressure for triangular bucket, maximum hydrodynamic pressure of the circular bucket is multiplied by parameter $\eta_{p m}$ (the ratio of maximum pressure of the triangular to circular bucket) [4]. Value of $\eta_{p m}$ for the largest chute spillway of Karoon III, as it is indicated in Figure 3, is equal to 1.75. Using this coefficient, the maximum dynamic pressure head for a triangular bucket becomes $56.55 \mathrm{~m}$.

\section{The objective functions definition}

Figure 4 shows the sketch of experimental set up performed at Water Research Centre [16] in which $\gamma$ is the deflector angle, $w$ is the bucket height, $s$ is the distance from the edge of bucket to the bottom of tail water channel, $V_{0}$ is the approach flow velocity, $h_{0}$ is the approach flow depth, and $a_{0}$ and $a_{u}$ are lower and 


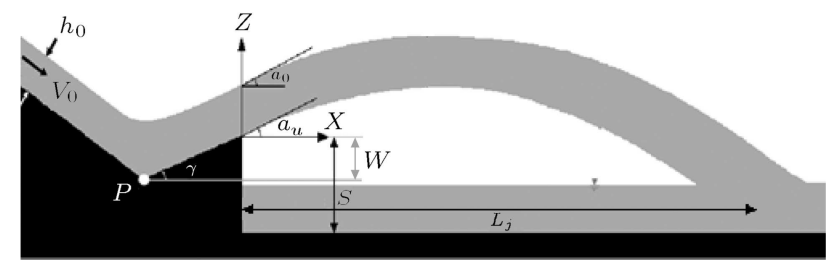

Figure 4. Schematic view of ski jump flow over a triangular flip-bucket.

upper jet takeoff angles. Also, the elevation difference $(s-w)$ between the approach flow and the tail water is constant.

In this research, a multi-objective optimization algorithm (NSGA-II) of Deb et al. [10] is used.

Here, two independent objective functions are used for designing chute spillway width and angle of triangular bucket. The first function, $f_{1}$, consists of scour depth, dynamic pressure head over bucket and jet length, while the second function, $f_{2}$, is related to construction volume of chute spillway. Objective function, $f_{1}$, is defined as follows:

$$
f_{1}=w_{h} h p / h p_{\max }+w_{z} z e / z e_{\max }-w_{l} l j / l j_{\max } .
$$

Here, $f_{1}$ represents the objective function, $h p$ represents the maximum dynamic pressure head on the bucket, ze represents scour depth, and $l j$ represents the jet length. Subsequently, these parameters have been defined. Other parameters including $w_{h}, w_{z}$, and $w_{l}$ are related to the maximum dynamic pressure weight, scour depth weight, and jet length weight, respectively.

Hojjati [7] proposed three equations as the outcome of study on 81 test cases:

I. Maximum dynamic pressure head equation on the bucket:

$$
\frac{h p}{h_{0}}=c \cdot \operatorname{Fr}^{a} \cdot(\tan (\gamma))^{b} .
$$

where Fr is the Froude number of chute spillway at start point and $a, b, c$ are obtained by Eqs. (4), (5), and (6), respectively:

$$
\begin{aligned}
& a=59.5\left(\frac{h_{0}}{L}\right)^{2}+13.43\left(\frac{h_{0}}{L}\right)+1.01, \\
& b=12.22\left(\frac{h_{0}}{L}\right)^{2}+3.17\left(\frac{h_{0}}{L}\right)+0.27, \\
& c=351.03\left(\frac{h_{0}}{L}\right)^{2}+99.45\left(\frac{h_{0}}{L}\right)+10.87 .
\end{aligned}
$$

Eq. (3) shows that when Froude number, the inlet flow depth, and bucket angle increase, the maximum dynamic pressure on the bucket increases (as these parameters increase, the velocity gradient along the bucket becomes larger).
II. Jet length:

$$
\frac{l j}{h_{0}}=d \cdot \operatorname{Fr}^{e} \cdot(\tan (\gamma))^{f},
$$

where $l j$ is jet length, $d, e$, and $f$ are presented by Eqs. (8), (9), and Eq. (10), respectively:

$$
\begin{aligned}
& d=67.46\left(\frac{h_{0}}{L}\right)^{2}-14.72\left(\frac{h_{0}}{L}\right)+1.07, \\
& e=-2.14\left(\frac{h_{0}}{L}\right)+0.52, \\
& f=-744.5\left(\frac{h_{0}}{L}\right)^{2}+52.81\left(\frac{h_{0}}{L}\right)+16.75 .
\end{aligned}
$$

According to the equation $V_{0}=$ Fr. $\sqrt{g h_{0}}\left(V_{0}\right.$ is upstream velocity and $g$ is acceleration due to gravity), with increase in $\mathrm{Fr}$ or $h_{0}$, the velocity of flow, and consequently the jet length would increase. Also, it is obvious for jet length to be independent of bucket height, because height variation just changes bucket length whose effect on energy dissipation is negligible.

III. Scour depth:

For estimation of scour depth and geometry, many empirical equations have been proposed from which Sen's [17] equation was used. The aforementioned formula was developed after examining several flip bucket prototypes in India and Russia. The equation in Metric system is presented as [17]:

$$
z e=0.9\left(\frac{q^{2}}{g}\right)^{\frac{1}{3}} H_{T}^{\frac{1}{4}} \frac{\theta}{\alpha_{1}},
$$

where ze represents final scour depth, $\theta$ represents jet impact angle, $H_{T}$ represents downstream head, $q$ represents discharge per unit width, and $\alpha_{1}$ is angle of jet impact at upstream side (Figure 5).

These parameters belong to circular buckets; therefore, they are modified by Hojjati [7] for triangular buckets according to the following steps:

1. The jet impact angle at downstream $(\theta)$ is calculated by:

$$
\frac{\theta}{\gamma}=0.586 . \mathrm{Fr}^{-0.308} \cdot\left(\frac{s+w}{h_{0}}\right)^{0.4} \cdot(\tan (\gamma))^{-0.774}
$$

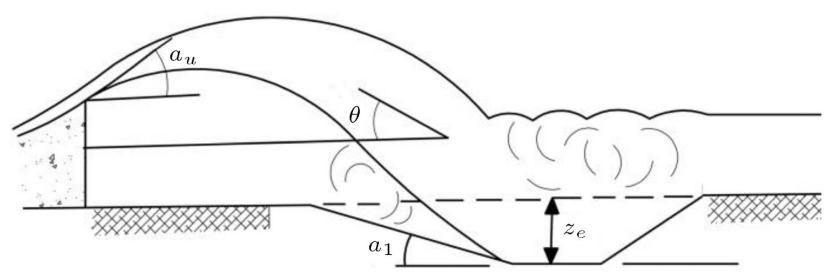

Figure 5. Geometrical parameters of scour. 


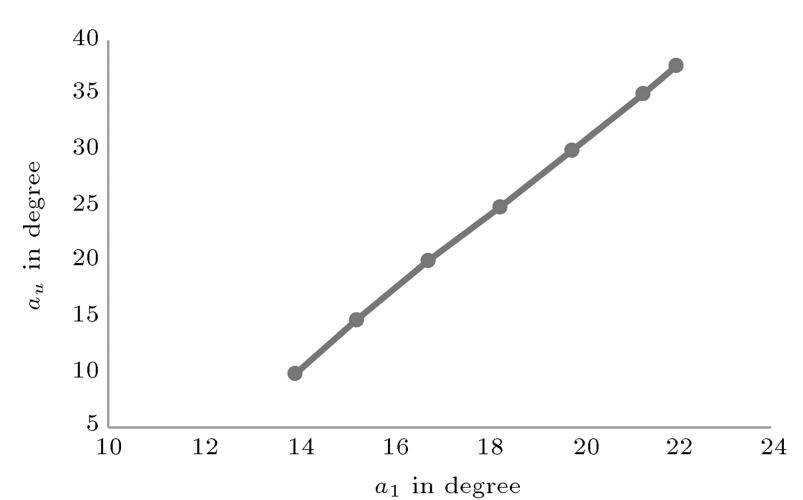

Figure 6. Calculation of $\alpha_{1}$ using Jet takeoff angle [17].

Table 1. Limitation of the present study.

\begin{tabular}{cccc}
\hline$\frac{h_{0}}{L}$ & $\boldsymbol{\gamma}$ (degree) & $\mathbf{F r}$ & $\frac{w}{L}$ \\
\hline $0.385-0.1155$ & $0-30$ & $1.14-3.14$ & $0.0288-0.0692$ \\
\hline
\end{tabular}

According to this equation, jet impact angle is a function of bucket geometry and upstream hydraulic conditions.

2. As it is shown in Figure 6, calculation of $\alpha_{1}$ requires $\alpha_{u}$ to be available. The latter variable can be yielded from Eq. (13). The equation for achieving lower jet trajectory angle is calculated by:

$$
\alpha_{u}=47.106 .(\tan (\gamma))^{0.856}
$$

Note that in Table 1, the limitations of the present study are listed as dimensionless parameters. $h p_{\max }$, $l j_{\max }$ and $z e_{\max }$ are the maximum values of $h p, z e$ and $l j$ in Eqs. (3), (7), and (11), respectively. To calculate $h p_{\max }, l j_{\max }, z e_{\max }$ due to complicated equations of $h p, l j$ and $z e$, a single objective optimization method is applied by adopting Genetic Algorithm approach. Parameters of Genetic Algorithm are determined as: initial population $=20$ chromosomes, crossover probability $=0.9$, number of genetic algorithm generations $=100$. At last, $h p_{\max }, l j_{\max }$, and $z e_{\max }$ are obtained as $65,143.9$, and 28.8 meters, respectively. Note that the values of $q$ and $H_{t}$ in Eq. (11) are implemented by considering spillway dimensions of Karoon III dam.

The second function, $f_{2}$, is related to normalized volume of construction materials of chute spillway. In the second objective function, this volume has been implemented and this parameter directly affects cost of spillway construction. This function is calibrated as a division of construction volume of chute spillway $(V)$ by construction volume of chute spillway of Karoon III $\left(V_{k}\right)$ :

$$
V=\left(L+\frac{w}{\sin \gamma}\right)\left(\left(\left(k+h_{0}+f\right) .2 t\right)+(b . k)\right)
$$

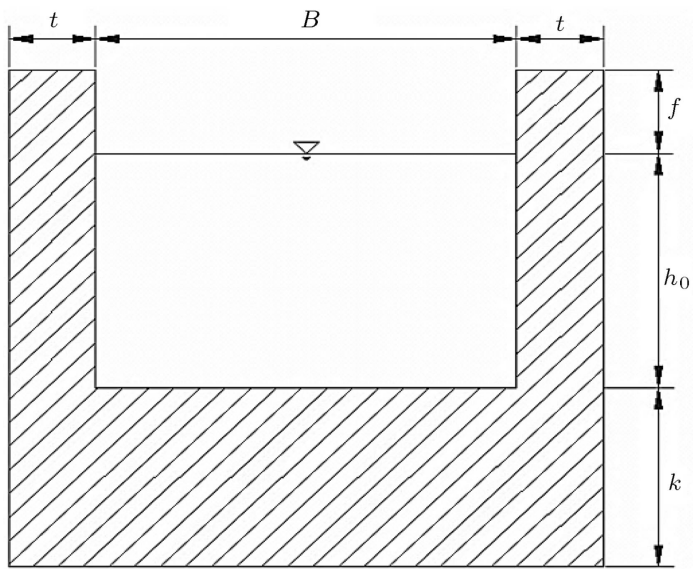

Figure 7. Cross section of spillway and bucket.

$$
f_{2}=V / V_{k},
$$

where $L=117 \mathrm{~m}$ and other parameters (Figure 7 ) are as follows: $t=1.8 \mathrm{~m}, k=9 \mathrm{~m}, B=15 \mathrm{~m}$ (chute width), and $f=0.1 h_{0} . V_{k}$ is obtained as $27549 \mathrm{~m}^{3}$ (with $h_{0}=13.38 \mathrm{~m}, w=4 \mathrm{~m}$, and $\gamma=30^{\circ}$ ).

\section{Results and discussion}

After sensitivity analysis, parameters of NSGA-II are determined as: initial population $=20$ chromosomes. This value is obtained through trial and error. It is the minimum initial population by which the most optimal answer can be attained. It means that if the initial population is increased, program application will take more time, but the optimal result will not change. Also, crossover probability $=0.9$, SBX index in NSGA-II algorithm $=0.5$, number of genetic algorithm generations $=150$. According to Table 2, five states have been considered for analyzing the data.

According to Table 2, five different states have been taken into consideration for analyzing the obtained data.

Table 3 shows the results of state no. 1 (considering equal weights for parameters of objective function $\left.f_{1}\right)$. In this table, the least value of the second objective function $\left(f_{2}\right)$ is estimated as 0.93 . It means that by using NSGA-II algorithms in spillway design, material volume can be reduced by $7 \%$. The amount of dynamic pressure and scour depth in this state is

Table 2. Different investigated states.

\begin{tabular}{cccccc}
\hline $\begin{array}{c}\text { Satate } \\
\text { no: }\end{array}$ & $\boldsymbol{w}_{\boldsymbol{z}}$ & $\boldsymbol{w}_{\boldsymbol{h}}$ & $\boldsymbol{w}_{\boldsymbol{l}}$ & $\mathbf{F r}$ & $\begin{array}{c}\boldsymbol{Q} \\
\left(\mathbf{m}^{3} / \mathbf{s}\right)\end{array}$ \\
\hline 1 & 0.333 & 0.333 & 0.333 & 2.2 & 4917 \\
2 & 0.1 & 0.1 & 0.8 & 2.2 & 4917 \\
3 & 0.1 & 0.8 & 0.1 & 2.2 & 4917 \\
4 & 0.8 & 0.1 & 0.1 & 2.2 & 4917 \\
5 & 0.333 & 0.333 & 0.333 & 3.2 & 1762 \\
\hline
\end{tabular}


Table 3. Results of optimizing by genetic method for state no. 1.

\begin{tabular}{cccccccc}
\hline $\boldsymbol{f}_{\mathbf{2}}$ & $\begin{array}{c}\boldsymbol{\gamma} \\
(\mathbf{d e g r e e})\end{array}$ & $\begin{array}{c}\boldsymbol{h}_{\mathbf{0}} \\
(\mathbf{m})\end{array}$ & $\begin{array}{c}\boldsymbol{V}_{\mathbf{0}} \\
(\mathbf{m} / \mathbf{s})\end{array}$ & $\begin{array}{c}\boldsymbol{B} \\
(\mathbf{m})\end{array}$ & $\begin{array}{c}\boldsymbol{h} \boldsymbol{p} \\
(\mathbf{m})\end{array}$ & $\begin{array}{c}\boldsymbol{l} \boldsymbol{j} \\
(\mathbf{m})\end{array}$ & $\begin{array}{c}\boldsymbol{z} \boldsymbol{e} \\
(\mathbf{m})\end{array}$ \\
\hline 0.93 & 30 & 13.35 & 25.18 & 14.63 & 63.88 & 131.2 & 25.29 \\
1.06 & 30 & 11.13 & 22.99 & 19.22 & 51.9 & 143.61 & 22.66 \\
0.6 & 30 & 10.18 & 21.99 & 21.97 & 49.19 & 142.44 & 21.47 \\
1.2 & 30 & 9.36 & 21.08 & 24.92 & 47.63 & 139.41 & 20.43 \\
1.32 & 30 & 8.74 & 20.37 & 27.62 & 46.76 & 136.05 & 19.61 \\
1.41 & 30 & 8.25 & 19.79 & 30.11 & 46.22 & 132.85 & 18.94 \\
1.5 & 30 & 7.78 & 19.22 & 32.88 & 45.76 & 129.27 & 18.28 \\
1.59 & 30 & 7.41 & 18.76 & 35.38 & 45.45 & 126.26 & 17.76 \\
1.69 & 30 & 7.03 & 18.27 & 38.28 & 45.12 & 122.86 & 17.2 \\
\hline
\end{tabular}

Table 4. Comparison of model and optimization results of Karoon III spillway.

\begin{tabular}{cccccc}
\hline & $\begin{array}{c}\boldsymbol{h}_{\mathbf{0}} \\
(\mathbf{m})\end{array}$ & $\begin{array}{c}\boldsymbol{V}_{\mathbf{0}} \\
(\mathbf{m} / \mathbf{s})\end{array}$ & $\begin{array}{c}\boldsymbol{h} \boldsymbol{p} \\
(\mathbf{m})\end{array}$ & $\begin{array}{c}\boldsymbol{\gamma} \\
(\mathbf{d e g r e e})\end{array}$ & $\begin{array}{c}\boldsymbol{B} \\
(\mathbf{m})\end{array}$ \\
\hline Hydraulic model & 13.38 & 24.5 & 56.55 & 30 & 15 \\
Design by genetic algorithm & 13.35 & 25.17 & 63.88 & 30 & 14.63 \\
Difference with current spillway & $0.2 \%$ & $2.7 \%$ & $12 \%$ & $0 \%$ & $2.5 \%$ \\
\hline
\end{tabular}

close to maximum values for $\mathrm{Fr}=2.2$ which does not sound satisfactory. The jet length is only $9 \%$ less than its maximum value. The table shows that increasing the materials volume (increasing the cost) will improve parameters of the first objective function $\left(f_{1}\right)$. Evaluation of the bucket angle demonstrates that with equal weighting coefficients, the optimum angle of bucket becomes 30 degrees. The reason behind the invariable angle, despite variable cost and approach depth, comes from the effect of dynamic pressure. Keeping weighting coefficients constant reduces the pressure head by $45 \mathrm{~m}$. This amount can be satisfied with 30 degrees bucket angle. However, the least pressure head occurs at Fr $=2.2$ which is $36 \mathrm{~m}$ (the value has been obtained through minimizing the objective function, $h p$, by NSGA-II algorithm). Table 3 indicates reduction of scour depth and pressure on the bucket due to an increase in spillway depth. This increase is restricted because of its effect on increasing $f_{2}$ and decreasing jet length, so a proper width will be chosen on the basis of project's financial condition.

Figure 8 shows the curve corresponding to interaction of functions $f_{1}$ and $f_{2}$ for state no. 1 in Table 2 . According to this figure, equal weights in the objective function $\left(f_{1}\right)$ can produce maximum value of 1.69 for the second objective function $\left(f_{2}\right)$.

In order to validate the design method, the results of state no. 1 have been compared to design characteristics of Karoon III dam. Results presented in the first row of Table 3 are very similar to the design parameters of Karoon III spillway. This row indicates that spillway design using NSGA-II algorithms reduces the volume of materials by seven percent $\left(f_{2}=0.93\right)$. The results of

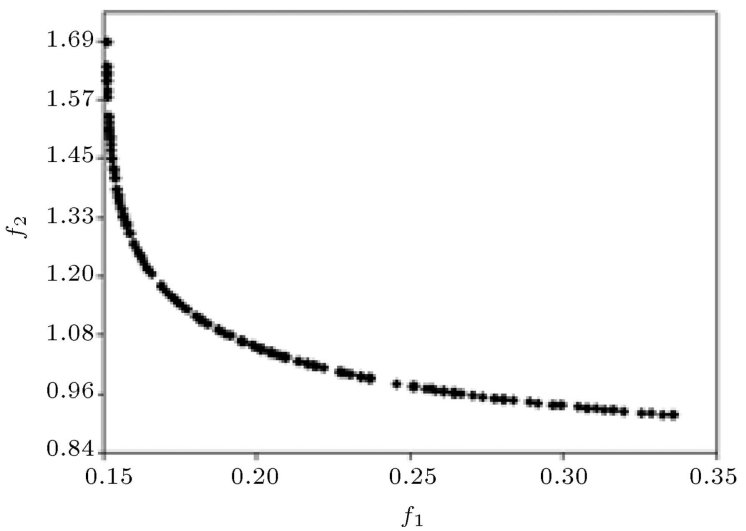

Figure 8. Optimized outcomes of NSGA-II algorithm.

this row are compared with the design characteristics of this spillway in Table 4. This table shows small and reasonable difference between design parameters of NSGA-II approach and a real case (less than 12\%). The largest discrepancy is seen in pressure parameter which should be due to the process of transforming the circular bucket dimensions to triangular one with the use of empirical equations (for example, using $\eta_{p m}$ for computing the dynamic pressure of triangular flip bucket).

According to Table 5, with increasing $w_{L}$, while the effective parameter in objective function is $L_{j}$ (state no. 2), the jet length ranges from 130.8 to 143.3 meters (the maximum jet length for $\mathrm{Fr}=2.2$ is $143.9 \mathrm{~m}$ ). Assessing the first and fourth rows of this table indicates that the rise of the second objective function by $14 \%$ leads the jet length to increase by $10 \%$, whereas the pressure and scour depth go down 
Table 5. Results of optimization by genetic method for state no. 2.

\begin{tabular}{cccccccc}
\hline $\boldsymbol{f}_{\mathbf{2}}$ & $\begin{array}{c}\boldsymbol{\gamma} \\
(\mathbf{d e g r e e})\end{array}$ & $\begin{array}{c}\boldsymbol{h}_{\mathbf{0}} \\
(\mathbf{m})\end{array}$ & $\begin{array}{c}\boldsymbol{V}_{\mathbf{0}} \\
(\mathbf{m} / \mathbf{s})\end{array}$ & $\begin{array}{c}\boldsymbol{B} \\
(\mathbf{m})\end{array}$ & $\begin{array}{c}\boldsymbol{h} \boldsymbol{p} \\
(\mathbf{m})\end{array}$ & $\begin{array}{c}\boldsymbol{l j} \\
(\mathbf{m})\end{array}$ & $\begin{array}{c}\boldsymbol{z} \boldsymbol{e} \\
(\mathbf{m})\end{array}$ \\
\hline 0.92 & 30 & 13.38 & 25.20 & 14.58 & 64.18 & 130.82 & 25.31 \\
0.97 & 30 & 12.26 & 24.13 & 16.62 & 57.91 & 139.4 & 24.25 \\
1.01 & 30 & 11.74 & 23.61 & 17.74 & 54.26 & 142.68 & 23.39 \\
1.06 & 30 & 11.1 & 22.96 & 19.30 & 51.81 & 143.62 & 22.63 \\
1.1 & 30 & 10.59 & 22.42 & 20.71 & 50.23 & 143.31 & 21.99 \\
\hline
\end{tabular}

Table 6. Results of optimization by genetic method for state no. 3 .

\begin{tabular}{cccccccc}
\hline $\boldsymbol{f}_{\mathbf{2}}$ & $\begin{array}{c}\boldsymbol{\gamma} \\
(\mathbf{d e g r e e})\end{array}$ & $\begin{array}{c}\boldsymbol{h}_{\mathbf{0}} \\
(\mathbf{m})\end{array}$ & $\begin{array}{c}\boldsymbol{V}_{\mathbf{0}} \\
(\mathbf{m} / \mathbf{s})\end{array}$ & $\begin{array}{c}\boldsymbol{B} \\
(\mathbf{m})\end{array}$ & $\begin{array}{c}\boldsymbol{h} \boldsymbol{p} \\
(\mathbf{m})\end{array}$ & $\begin{array}{c}\boldsymbol{l} \boldsymbol{j} \\
(\mathbf{m})\end{array}$ & $\begin{array}{c}\boldsymbol{z e} \\
(\mathbf{m})\end{array}$ \\
\hline 0.92 & 29 & 13.41 & 25.23 & 14.53 & 64.27 & 129.95 & 25.51 \\
1.46 & 17.44 & 8.3 & 19.85 & 29.84 & 44.03 & 109.46 & 21.73 \\
1.86 & 10.42 & 7.1 & 18.36 & 37.72 & 40.5 & 82.63 & 19.86 \\
2.2 & 8.27 & 6.36 & 17.38 & 44.49 & 38.39 & 69.87 & 18.91 \\
2.65 & 8 & 5.53 & 16.20 & 54.87 & 36.61 & 61.72 & 17.48 \\
3.1 & 8 & 4.92 & 15.28 & 65.39 & 35.12 & 56.13 & 16.31 \\
3.5 & 8 & 4.5 & 14.62 & 74.75 & 33.18 & 52.12 & 15.46 \\
\hline
\end{tabular}

Table 7. Results of optimization by genetic method for state no. 4 .

\begin{tabular}{cccccccc}
\hline $\boldsymbol{f}_{\mathbf{2}}$ & $\begin{array}{c}\boldsymbol{\gamma} \\
(\mathbf{d e g r e e})\end{array}$ & $\begin{array}{c}\boldsymbol{h}_{\mathbf{0}} \\
(\mathbf{m})\end{array}$ & $\begin{array}{c}\boldsymbol{V}_{\mathbf{0}} \\
(\mathbf{m} / \mathbf{s})\end{array}$ & $\begin{array}{c}\boldsymbol{B} \\
(\mathbf{m})\end{array}$ & $\begin{array}{c}\boldsymbol{h} \boldsymbol{p} \\
(\mathbf{m})\end{array}$ & $\begin{array}{c}\boldsymbol{l j} \\
(\mathbf{m})\end{array}$ & $\begin{array}{c}\boldsymbol{z e} \\
(\mathbf{m})\end{array}$ \\
\hline 0.92 & 30 & 13.34 & 25.17 & 14.65 & 63.87 & 131.31 & 25.27 \\
0.97 & 30 & 12.49 & 24.35 & 16.17 & 58.07 & 139.22 & 24.28 \\
1.76 & 30 & 6.79 & 17.96 & 40.33 & 44.91 & 120.61 & 16.85 \\
2.21 & 30 & 5.56 & 16.25 & 54.43 & 43.65 & 108.36 & 15.09 \\
2.64 & 30 & 4.94 & 15.32 & 64.99 & 42.42 & 99.43 & 13.92 \\
2.91 & 30 & 4.59 & 14.76 & 72.56 & 41.64 & 94.75 & 13.33 \\
\hline
\end{tabular}

by $10 \%$ which seems to be not cost-effective. Based on the results of this table, by considering the second state for weight of objective function, $f_{1}$, the bucket and spillway design becomes more satisfactory. In this state, due to small weight for pressure parameter, the bucket angle becomes 30 degrees again.

A closer look at Table 6 (state no. 3) demonstrates the fact that by increasing $w_{h}$, as the main parameter in the objective function, $h p$, the pressure head ranges from 64.2 to 33.9 meters (minimum dynamic pressure head for $\mathrm{Fr}=2.2$ is $33.9 \mathrm{~m}$ ). The results of this table show that getting a pressure head less than 45 meter requires the bucket angle to be smaller than 30 degrees. It can also be noticed from the results of Section 3 (in this section, the reduction of bucket angle and approach flow depth caused the dynamic pressure on bucket drop down) that if minimizing the pressure parameter is desired, depth of the angle and inlet flow will become less than their values in state no. 2 , and this makes the spillway become remarkably wide.

Additional information that can be deduced from
Table 6 includes conditions of a state with pressure head below $40.5 \mathrm{~m}$ in which the spillway width exceeds $34.2 \mathrm{~m}$. It indicates that in such conditions, wider spillway is needed to be designed which is not economic. However, reduction of scour depth (due to reduction of bucket angel and flow velocity) is frugal. As a result of decline in velocity and pressure of the flow, the bucket maintenance costs would go down (velocity decline reduces the risk of cavitation and consequent damages). One should notice that by reducing the bucket angle and the flow depth, the jet length becomes shorter. It is not appropriate and should be taken into consideration in process of the design.

Table 7 illustrates that if the effective parameter, $w_{z}$, in the first objective function, ze, rises (state no. 4 ), the scour depth will change from 25.2 to $13.33 \mathrm{~m}$. The table shows that in order to have a shallow scour hole, a wide spillway is needed which is not a costeffective solution. In this state, the low weight for pressure parameter results in bucket angle of 30 degrees for different cases. This set up presents a $36.5 \mathrm{~m}$ wide 
Table 8. Results of optimization by genetic method for state no. 5 .

\begin{tabular}{cccccccc}
\hline $\boldsymbol{f}_{\mathbf{2}}$ & $\begin{array}{c}\boldsymbol{\gamma} \\
(\mathbf{d e g r e e})\end{array}$ & $\begin{array}{c}\boldsymbol{h}_{\mathbf{0}} \\
(\mathbf{m})\end{array}$ & $\begin{array}{c}\boldsymbol{V}_{\mathbf{0}} \\
(\mathbf{m} / \mathbf{s})\end{array}$ & $\begin{array}{c}\boldsymbol{B} \\
(\mathbf{m})\end{array}$ & $\begin{array}{c}\boldsymbol{h} \boldsymbol{p} \\
(\mathbf{m})\end{array}$ & $\begin{array}{c}\boldsymbol{l j} \\
(\mathbf{m})\end{array}$ & $\begin{array}{c}\boldsymbol{z e} \\
(\mathbf{m})\end{array}$ \\
\hline 0.49 & 30 & 11.56 & 33.44 & 4.56 & 59.15 & 159.57 & 26.54 \\
0.53 & 30 & 8.05 & 28.44 & 7.70 & 51.19 & 146.61 & 21.34 \\
0.56 & 30 & 7.14 & 26.78 & 9.21 & 50.95 & 140.01 & 19.86 \\
\hline
\end{tabular}

spillway and scours depths of less than $16.85 \mathrm{~m}$ which is not a cost-effective design.

Table 8 contains design values for a spillway with weighting coefficients of state no. $5: Q=1762 \mathrm{~m}^{3} / \mathrm{sec}$, $\mathrm{Fr}=3.2$, and $w=4 \mathrm{~m}$. By using single objective optimization method, the values of $h p_{\max }, l j_{\max }$, and $z e_{\max }$ become $73.8,162$, and 33.3 meters, respectively. The cost (construction volume of chute spillway) and width of chute spillway are expected to decrease the designed discharge which is reduced by $70 \%$. Also, due to constant weighting coefficients, the bucket angle changes according to state no. 1.

\section{Conclusions}

In this paper, a NSGA-II algorithm, which solves multiobjective problems, is utilized in optimal design of the width of a chute spillway and angle of a triangular flip bucket. A design method is introduced which performs a two-objective optimization through defining two separate objective functions. For validation process, results of objective function, $f_{1}$, with equal weighting coefficients are compared with design conditions of Karoon III dam. Investigation of equally chosen weighted parameters in objective function, $f_{1}$, shows that the optimum bucket angle obtained by NSGA-II algorithm is equal to 30 degrees for different costs and inlet flow depths. The differences are less than $12 \%$ which go to the pressure parameter. According to the investigation results, giving more weight to the jet length parameter in objective function will make the design of the bucket and spillway more suitable. If the pressure head is considered as the most effective parameter in the first objective function, it is not a cost-effective approach; however, the reduction in scour depth brings about a positive financial outcome. Moreover, this decline in velocity and pressure causes the maintenance cost to decrease. Finally, if the most effective parameter in objective function, $f_{1}$, is considered to be the scour depth, it is observed that to have a shallower scour depth, a wider spillway is needed which is not costeffective.

\section{Acknowledgment}

The authors thank Dr. Jafar Yazdi for assistance with Optimization part that greatly improved the manuscript.

\section{Nomenclature}

\begin{tabular}{|c|c|}
\hline$\gamma$ & Deflector angle \\
\hline$W$ & Bucket height \\
\hline$B$ & Chute spillway width \\
\hline$S$ & $\begin{array}{l}\text { Distance from the edge of bucket to } \\
\text { the bottom of tail water channel }\end{array}$ \\
\hline$V_{0}$ & Approach flow velocity \\
\hline$h_{0}$ & Approach flow depth \\
\hline$a_{0}$ & Upper jet takeoff angles \\
\hline$a_{u}$ & Lower jet takeoff angles \\
\hline$f_{1}$ and $f_{2}$ & Objective functions \\
\hline$w_{h}$ & Maximum dynamic pressure weight \\
\hline$w_{z}$ & Scour depth weight \\
\hline$w_{l}$ & Jet length weight \\
\hline$h p$ & Maximum dynamic pressure head \\
\hline$z e$ & Scour depth \\
\hline$l j$ & Jet length \\
\hline$h p_{\max }$ & $\begin{array}{l}\text { Maximum value of maximum dynamic } \\
\text { pressure head in Eq. (3) }\end{array}$ \\
\hline$z e_{\max }$ & $\begin{array}{l}\text { Maximum value of scour depth in } \\
\text { Eq. (11) }\end{array}$ \\
\hline$l j_{\max }$ & Maximum value of jet length in Eq. (7) \\
\hline $\operatorname{Fr}$ & Froude number \\
\hline$\theta$ & Jet impact angle \\
\hline$H_{T}$ & Downstream head \\
\hline$Q$ & Discharge per unit width \\
\hline$\alpha_{1}$ & Angle of jet impact at upstream side \\
\hline$G$ & Acceleration due to gravity \\
\hline$L$ & Chute length \\
\hline$R$ & Radius of circular bucket \\
\hline$\beta$ & Angle of circular bucket \\
\hline$Q$ & Discharge \\
\hline$V$ & Construction volume of chute spillway \\
\hline$V_{k}$ & $\begin{array}{l}\text { Construction volume of chute spillway } \\
\text { of Karoon III }\end{array}$ \\
\hline
\end{tabular}

\section{References}

1. Vischer, D.L. and Hager, W.H. "Energy dissipators", IAHR Hydr. Struct. Des. Manual 9, Balkema, Rotterdam, the Netherlands (1995). 
2. Juon, R. and Hager, W.H. "Flip bucket without and with deflectors", Journal of Hydraulic Engineering, 126(11), pp. 837-845, (2000). DOI: 10.1061/(ASCE)0733-9429(2000)126:11(837),

3. Heller, V., Hager, W.H. and Minor, H.-E. "Ski jump hydraulics", J. Hyd. Eng., 131(5), pp. 347-355 (2005). DOI: 10.1061/ (ASCE) 0733-9429(2005)131:5(347),

4. Steiner, R., Heller, V., Hager, W.H. and Minor, H.E. "Deflector ski jump hydraulics", Journal of Hydraulic Engineering, 134(5), pp. 562-571 (2008). DOI: 10.1061/(ASCE)0733-9429(2008)134:5(562),

5. Pfister, M. "Chuteaerators: Air transport due to internal flow features (Schussrinnenbelüfter: Lufttransport ausgelöst durch interne bflussstruktur)", Laboratory of Hydraulics, Hydrology and Glaciology (VAW), H.-E. Minor, Ed., ETH: Zurich (in German) (2008).

6. Pfister, M. "Jet impact angle on chute downstream of aerator", Proc., 4th IAHR Int., Symp., on Hydraulic Structures, Porto, Portugal (2012).

7. Hojjati, S.H. "Numerical investigation of flow hydraulics in triangular flip buckets", M.S. Thesis, Tarbiat Modares University, Tehran, Iran (2013).

8. Azamathulla, H.MD., Ghani, A.AB., Zakaria, N.A., Lai, S.H., Chang, C.K., Leow, C.S. and Abuhasan, Z. "Genetic programming to predict ski-jump bucket spill-way scour", Journal of Hydrodynamics, Ser. $B, 20(4)$, pp. 477-484, (2008). DOI: 10.1016/S10016058(08)60083-9,

9. Srinivas, N. and Deb, K. "Multi-objective function optimization using non-dominated sorting genetic algorithms", Evolutionary Computation, 2(3), pp. 221248 (1995).

10. Deb, K., Agrawal, S., Pratap, A. and Meyarivan, T. "A fast elitist non-dominated sorting genetic algorithm for multi-objective optimization: NSGA-II", Lecture Notes in Computer Science 1917/2000, pp. 849-858 (2000). DOI: $10.1007 / 3-540-45356-3 \_83$,

11. Reddy, M.J. and Kumar, D.N. "Multi-objective differential evolution with application to reservoir system optimization", Journal of Computing in Civil Engineering, 21(2), pp. 136-146 (2007). DOI: 10.1061/(ASCE)0887-3801(2007)21:2(136),

12. Zahraie, B. and Tavakolan, M. "Stochastic timecost-resource utilization optimization using nondominated sorting genetic algorithm and discrete fuzzy sets", Journal of Construction Engineering and Management, 135(11), pp. 1162-1171 (2009). DOI: 10.1061/(ASCE)CO.1943-7862.0000092,

13. Malekmohammadi, B., Zahraie, B. and Kerachian, R. "Ranking solutions of multi-objective reservoir operation optimization models using multi-criteria decision analysis", Expert Systems with Applications, 38(6), pp. 7851-7863 (2011).

14. Behzadian, K., Alimohammadnejad, M., Ardeshir, A., Jalilsani, F. and Vasheghani, H. "A novel approach for water quality management in water distribution systems by multi-objective booster chlorination", International Journal of Civil Engineering, 10(1), pp. 51-60 (2012).

15. Goldberg, D.E. "Genetic algorithms in search", Optimization and Machine Learning, ISBN: 0-201-15767-5 (1998).

16. Water. Res. Center. "Final report on: Hydraulic model study on Karoon III spillway" Rep. No. 198, Tehran, Iran (1996).

17. Sen, P. "Spillway scour and design of plunge pool", Water and Energy International, 41(1), pp. 51-68 (1984).

\section{Biographies}

Seyed Hami Hojjati received his BSc degree in Civil Engineering from Mazandaran University, Babol, Iran and his MS degree in Hydraulic Engineering from Tarbiat Modares University, Tehran, Iran. He is currently a PhD student of Hydraulic Engineering in Amirkabir University, Tehran, Iran. His research interests include flow control structures, flow and sediment transport in rivers, energy dissipation structures, and soft computing.

Seyed Hani Hojjati received the BSc degree in Power Engineering from Mazandaran University, Babol, Iran, and the MSc degree in Communication Systems Engineering from Babol University of Technology, Babol, Iran. He is currently pursuing the $\mathrm{PhD}$ degree in Communications in the Babol University of Technology, Babol, Iran. His current research interests include sensor networks, soft computing, pattern recognition, and machine learning.

Seyed Ali Akbar Salehi Neyshabouri received his BSc degree in Structural Engineering from Sharif University, Tehran, Iran, his MSc degree in Hydraulic Engineering from Newcastle University, Newcastle, UK, and his PhD Degree in Hydraulic Engineering from Liverpool University, Liverpool, UK. He is currently a Professor of Hydrualic Structures in Tarbiat Modares University, Tehran, Iran. His research interests include hydrodynamics, sediment transport, and computational fluid dynamic. 